\title{
Effect of tranexamic acid in prevention of postpartum hemorrhage in elective caesarean delivery: a randomized controlled study
}

\author{
Abd El-Naser Abd El-Gaber ${ }^{1}$, Hazem H. Ahmed ${ }^{1}$, Mustafa M. Khodry ${ }^{1}$, Ahmed M. Abbas ${ }^{2 *}$
}

${ }^{1}$ Department of Obstetrics and Gynecology, Faculty of Medicine, South Valley University, Qena, Egypt

${ }^{2}$ Department of Obstetrics and Gynecology, Faculty of Medicine, Assiut University, Assiut, Egypt

Received: 03 November 2018

Accepted: 06 December 2018

*Correspondence:

Dr. Ahmed M. Abbas,

E-mail: bmr90@hotmail.com

Copyright: () the author(s), publisher and licensee Medip Academy. This is an open-access article distributed under the terms of the Creative Commons Attribution Non-Commercial License, which permits unrestricted non-commercial use, distribution, and reproduction in any medium, provided the original work is properly cited.

\begin{abstract}
Background: Postpartum hemorrhage is the ugly ghost that most obstetricians believe because many cases unpredicted and may be associated with rapid patient deterioration that may lead mortality or developing serious longterm morbidities. The objective of this study is to assess the efficacy of slowly intravenous administration of tranexamic acid in prevention and decline the severity of postpartum hemorrhage immediately prior to elective caesarean section.

Methods: A double blinded, randomized, case control trial carried out at Obstetrics and Gynecology Department, Faculty of Medicine, South Valley University, Egypt from May 2017 to April 2018. This study was conducted on 500 full term pregnant women underwent elective caesarean section. The patients were divided randomly into: Group A (study group) included 250 patients received tranexamic acid $1 \mathrm{gm}$ slowly iv over 2 minutes at least 10 minutes before operation started and Group B (control group) included 250 patients that received placebo (normal saline $\mathrm{NaCl} 0.9 \%$ ). Results: Incidence of PPH in group A and group B were (4.4\% and 6.8) respectively, $1.2 \%$ in group A and $2.8 \%$ in group B had severe degree of PPH. Amount of blood loss immediately after placental delivery up to first 6 hours postoperative was statistically significant increase in placebo group than tranexamic acid group with $p$ value $<0.001$. Conclusions: Tranexamic acid administration few minutes prior to elective cesarean section was effective in reducing the incidence and severity of PPH and decreased the use of additional uterotonic drugs and additional surgical interventions.
\end{abstract}

Keywords: Elective cesarean delivery, Postpartum hemorrhage, Tranexamic acid

\section{INTRODUCTION}

Primary postpartum hemorrhage $(\mathrm{PPH})$ represents the major reason of maternal deaths, with global prevalence about $6 \% .^{1}$ In developing countries obstetric hemorrhage is the most common cause of female mortality in the child bearing period which represents $27 \%$ of all maternal deaths throughout world. ${ }^{2}$

Primary postpartum hemorrhage is considered if blood loss within first 24 hours after delivery (vaginal or cesarean) equaled or exceeded $1,000 \mathrm{ml}$ or associated with manifestations of hypovolemia inspite of amount of blood loss. ${ }^{3}$ Traditional definitions depended on mode of delivery, if estimated blood loss $>500 \mathrm{ml}$ with vaginal delivery and $>1000 \mathrm{ml}$ with cesarean delivery were considered primary postpartum hemorrhage. ${ }^{4}$

Postpartum hemorrhage risk factors include all causes of uterine atony (previous history of atonic PPH, macrosomic baby, multiparty, considerable anemia, elective Caesarean delivery (CD), prolonged and or 
augmented labor), abnormal placentation or morbidly adherent placenta, coagulation defect, blood diseases, birth canal injury, uterine rupture and sometimes PPH can be occurred in absence of any obvious risk factors. ${ }^{5,6}$ $\mathrm{CD}$ can be considered as one of most common risk factors for atonic PPH particularly with global increase in the cesarean delivery rate. ${ }^{7}$

Tranexamic acid (TXA) is an amino acid lysine synthetic derivative which has its anti-fibrinolytic effect from the reversible blockade of lysine binding sites on molecules of plasminogen. ${ }^{8}$ Since the 1960s TXA has been prescribed off-label in order to minimize blood loss for different surgeries that associated with marked blood loss such as orthopedic and cardiac surgical procedures. TXA also had been used in trauma surgeries to minimize blood loss. ${ }^{9}$ Following inclusion of TXA in the (Essential Medicines Model List) for cardiac surgeries, in 2013 it had been included for use in trauma of adults with ongoing excessive blood loss or in patients who are at risk of massive hemorrhage through 8 hours of injury. ${ }^{10}$

Many medications and various surgical interventions are used as preventive measures that could at least reduce postpartum hemorrhage during CD. ${ }^{11} \mathrm{TXA}$ is a promising agent, easy to administer, cheap, and can be added to the other routine management in hospitals deliveries. ${ }^{12}$

The aim of this study was to assess the efficacy of slowly intravenous administration of TXA in prevention and decline the severity of PPH in elective CD.

\section{METHODS}

This prospective double blinded, randomized trial was conducted on 500 full term pregnant women underwent elective caesarean delivery at Obstetrics and Genecology Department, Qena University Hospital, South Valley University, Egypt from May 2017 to April 2018.

\section{Inclusion criteria}

- All patients recruited in this study underwent elective caesarean delivery for obstetric indications.

\section{Exclusion criteria}

- Multiple pregnancy, macrosomic baby, IUFD, preterm baby, polyhydramnios, presence of uterine fibroids, placenta previa and morbidly adherent placenta, bleeding disorders, presence of any degree of anemia, any medical disorders as heart or liver diseases, anticoagulant therapy, history of allergy to tranexamic acid.

A good counselling and written concept was taken from each patient participated in the study according to the Committee of medical Ethics of Faculty of Medicine of South Valley university. A detailed full history was taken from each patient included in this study with general and obstetric examination and all routine investigations needed for patient preparation for operation also obstetric ultrasound for fetal assessment and confirmation of diagnosis and exclude cases that mentioned above in exclusion criteria.

\section{Randomization and blinding}

Patients were classified randomly into two groups using a computer-generated randomization system (Microsoft office excel, 2010). The list of randomization was concealed and expressed by sequentially numbered, sealed opaque envelopes just prior to intervention. Each number had been correlated to a ready prepared $10 \mathrm{ml}$ syringe that contains $10 \mathrm{ml}$ of completely colourless solution.

Packing process, sealing and numbering had been performed by 2 separate persons not related to the investigator. Neither the investigator nor the surgeon awarded about what each patient received (doubleblinding). The codes tables of randomization had been hidden to the investigator till the study ended.

\section{Intervention}

Group A (Tranexamic acid group) included 250 patients received tranexamic acid (Kapron, Amoun industry) 1gm slowly iv over 2 minutes at least 10 minutes before skin incision and Group B (Placebo group) included 250 patients that received placebo (normal saline $\mathrm{NaCl} 0.9 \%$ ). All patients had lower segment caesarean section. When baby had been delivered, 10 units of oxytocin in $500 \mathrm{ml}$ of normal saline were administered through intravenous drip over 15 minutes. The amount of blood loss was assessed from time of placenta delivery to the end operation through measuring volume of blood in the suction bottle and reweighing towels used during operation. After end of operation authors assessed the amount of blood loss and for the next 6 hours postoperative by reweighing of soaked pads.

Hemoglobin level and haematocrit value were checked pre and 24 hours postoperative. Patients were observed during and postoperative for any hemodynamic instability and managed according to need (additional uterotonic drugs or cross matched blood transfusion or surgical interventions as B Lynch suture or urgent hysterectomy). The newborns were assessed by neonatologist for fetal distress using Apgar score 1 and after 5 minutes and persistent marked distressed cases were incubated in NICU. All data were documented on case record form.

\section{Statistical analysis}

The data was collected coded, tabulated and finally statistically analyzed, using SPSS program (software version 22.0). Descriptive statistics were done for numerical parametric data as mean \pm SD (standard deviation). Inferential analyses were done for quantitative 
variables using independent t-test in cases of two independent groups with parametric data. Inferential analyses were done for qualitative data using Chi square test for independent variables. The level of significance was taken if $\mathrm{P}$ value $<0.05$, otherwise was considered non-significant.

\section{RESULTS}

No statistical significant difference regarding the baseline criteria; age, parity, body mass index and gestational age of both groups (Table 1).

Table 1: Demographic data of both groups.

\begin{tabular}{|l|l|l|l|l|}
\hline & Group A $(\mathbf{n = 2 5 0 )}$ & Group B $(\mathbf{n = 2 5 0})$ & t & p \\
\hline Age (years) & $27.14 \pm 4.986$ & $26.77 \pm 4.942$ & 0.847 & 0.397 \\
\hline BMI $\left(\mathrm{kg} / \mathrm{m}^{2}\right)$ & $32.88 \pm 2.76$ & $33.59 \pm 3.22$ & 1.489 & 0.138 \\
\hline Gestational age (weeks) & $38.32 \pm 1.124$ & $38.24 \pm 1.518$ & 0.670 & 0.503 \\
\hline Parity & $1.74 \pm 1.461$ & $1.61 \pm 1.286$ & 0.372 & 0.270 \\
\hline
\end{tabular}

$\mathrm{p}>0.05$ (data expressed as mean $\pm \mathrm{SD}$ )

Table 2: Comparison between the two groups according to amount of blood loss.

\begin{tabular}{|l|l|l|l|l|}
\hline Blood loss $(\mathrm{cc})$ Mean \pm SD & Group A $(\mathbf{n = 2 5 0})$ & Group B $(\mathrm{n}=250)$ & $\mathrm{t}$ & P \\
\hline During CS procedure & $387.68 \pm 93.05$ & $560.79 \pm 107.46$ & -19.26 & $<0.001 *$ \\
\hline From end of CS procedure up to 6 hours postoperative & $159.16 \pm 50.95$ & $232.68 \pm 65.18$ & -14.05 & $<0.001 *$ \\
\hline During CS procedure + next 6 hours postoperative & $546.84 \pm 106.13$ & $793.99 \pm 141.21$ & -22.12 & $<0.001 *$ \\
\hline
\end{tabular}

*Significant (data expressed as mean $\pm \mathrm{SD}$ )

Table 3: Comparison between Group I and Group II as regard to pre and postoperative hemoglobin (g/dl) and hematocrit $(\%)$ levels.

\begin{tabular}{|l|l|l|l|l|}
\hline & Group A $(\mathbf{n}=250)$ & Group B $(\mathrm{n}=250)$ & $\mathrm{t}$ \\
\hline Preoperative $\mathrm{Hb}(\mathrm{gm} / \mathrm{dl})$ & $11.29 \pm 0.97$ & $11.33 \pm 1.03$ & -0.516 & 0.606 \\
\hline 24 hours Postoperative $\mathrm{Hb}(\mathrm{gm} / \mathrm{dl})$ & $10.81 \pm 0.92$ & $10.27 \pm 0.89$ & 6.679 & $<0.001^{*}$ \\
\hline Reduction in $\mathrm{Hb}(\mathrm{gm} / \mathrm{dl})$ & $0.475 \pm 0.23$ & $1.06 \pm 0.31$ & -23.923 & $<0.001^{*}$ \\
\hline Preoperative $\mathrm{Hct}(\%)$ & $32.77 \pm 2.97$ & $33.01 \pm 3.02$ & -0.892 & 0.373 \\
\hline 24 hours Postoperative Hct $(\%)$ & $31.96 \pm 2.89$ & $30.80 \pm 2.74$ & 4.599 & $<0.001^{*}$ \\
\hline Reduction in Hct $(\%)$ & $0.85 \pm 0.47$ & $2.21 \pm 1.13$ & -17.54 & $<0.001^{*}$ \\
\hline
\end{tabular}

*Significant (data expressed as mean \pm SD)

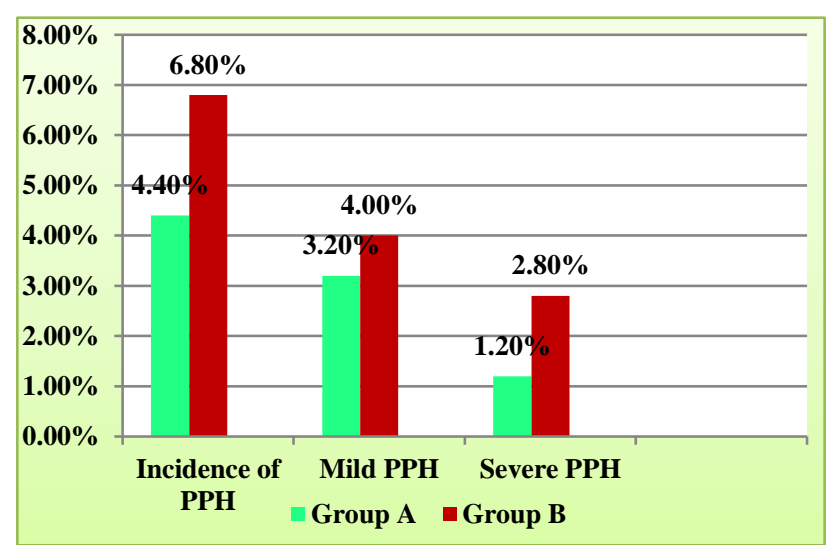

Figure 1: Incidence and degrees of PPH in both groups.

The incidence of PPH in group A and group B were (4.4\% and 6.8) respectively, as regard to severity of $\mathrm{PPH}$ in both groups, only 3 cases $(1.2 \%)$ had severe degree of
PPH in group A, while 7 cases $(2.8 \%)$ had severe degree of PPH with a highly statistically significant difference between the two groups with $p$ value $<0.001$ (Figure 1).

Amounts of blood loss had a highly statistically significant difference between the two groups (less in group A) with $\mathrm{p}$ value $<0.001$ (Table 2 ). This was applied on the blood loss during CS and after 6 hours from the end of CS.

As regard to change in hemoglobin level and hematocrit value pre and 24 hours postoperative were highly statistically significant differences between the two groups with $\mathrm{p}$ value $<0.001$ (Table 3 ).

There were highly statistically significant differences between the two groups as regard to additional uterotonic agents and additional surgical interventions used in control of PPH and in blood transfusion needed with $\mathrm{p}$ value $<0.001$ (Figure 2). 
Neonatal outcomes were comparable between both groups. No difference either in the rate of NICU admission or neonatal RDS.

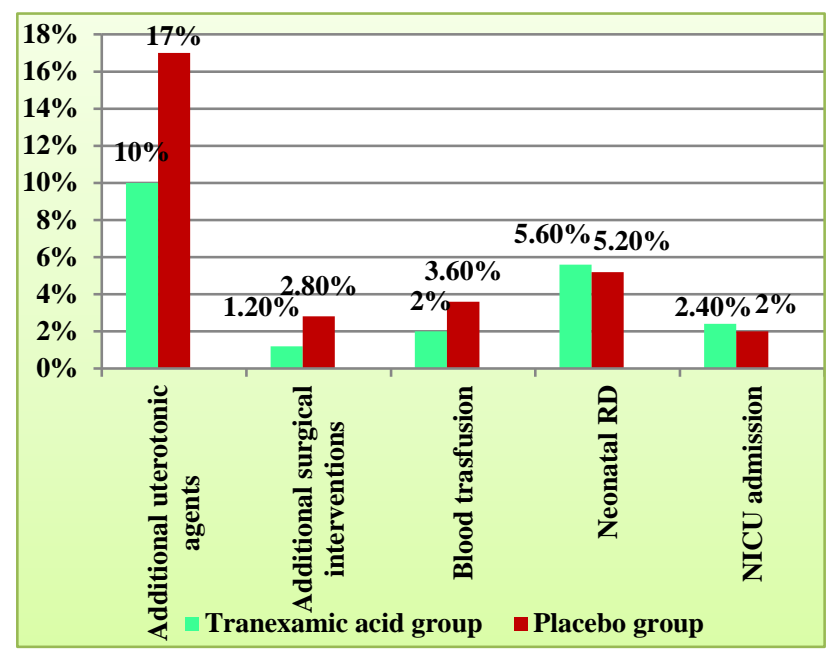

Figure 2: Incidence of additional uterotonic drugs, additional surgical intervention, blood transfusion and neonatal outcome in both groups.

\section{DISCUSSION}

Maternal mortalities due to obstetric hemorrhage particularly PPH represent the first cause of maternal deaths in child bearing period in developing countries and about $43 \%$ of them present in Sub-Saharan and Northern Africa. ${ }^{13} 45$ per 100,000 live births represent the number of maternal mortality in Egypt that had been registered in 2013 according to the World Health Organization data. ${ }^{14}$ Maternal mortality has been decreased in Egypt in period 1995 to 2008, where the rate dropped from 230 per 100,000 live births to 66 deaths per 100,000 live births, as regard to the estimation reported from repetitive Demographic and Health Surveys. ${ }^{15}$

Two surveys for national maternal mortality had been conducted in the period 1992 to 1993 and in the period 2000 to 2001, both surveys reported that approximately $30 \%$ of all cases of maternal deaths caused by PPH. ${ }^{16}$ Another study had been reported in Egypt on maternal mortality discussed the main causes for avoidable deaths were suboptimal care, delay in the recognition of the case, improper antenatal care and finally lack of supplies include blood and its derivatives e.g. fresh frozen plasma and platelets. ${ }^{17}$ Many medications have been tried in prevention of postpartum hemorrhage, authors used tranexemic acid in this study because it has affordable price, easily administered and has rare side effects. In this study the base line of patient's demographic data was matched in both groups with no significant difference (Table 1).

Incidence of PPH was significantly low in tranexamic group $(4.4 \%)$ than placebo group $(6.8 \%)$ (Figure 1). In this study the blood loss during elective cesarean section after delivery of placenta and up to 6 hours postoperative was significantly low in tranexamic group (Table 2) and this result agreed with that had been reported with different studies as Gai MY et al and Sekhavat et al as they assessed the blood loss during cesarean section and up to 2 hours postoperative. ${ }^{18,19}$

As regard to changes in hemoglobin level and hematocrit value 24 hours postoperative in this study, the changes were significantly high in placebo group than tranexamic group (Table 3). Also the need for additional uterotonic drugs, additional surgical interventions or blood transfusion were significantly less in tranexamic group (Figure 2), these results were agreed with many previous studies as what had been reported by the meta-analysis of the $9 \mathrm{RCTs}$ for evaluation the efficacy of prophylactic tranexamic acid in decrease postpartum hemorrhage at cesarean delivery, which showed, tranexamic acid was associated with a significant reducing postpartum blood loss (low incidence and low severity), a significantly lower hemoglobin level drop postoperative and less need for additional uterotonic drugs. ${ }^{20}$

Also, the results of this study agreed with another metaanalysis has been published as a Cochrane Review that evaluated the efficacy of tranexamic acid in reduction of postpartum blood loss, but this meta-analysis included vaginal and cesarean deliveries studies. ${ }^{21,22}$

As regard to neonatal outcome in both groups in this study, neonatal respiratory distress and admission to neonatal intensive care were insignificant in both groups so tranexamic acid has no effect on neonatal outcome, although tranexamic acid may have rare serious adverse effects on neonatal outcome because tranexamic acid cross placenta to fetal cord blood. ${ }^{23}$

\section{CONCLUSION}

Tranexamic acid administration few minutes prior to elective $\mathrm{CD}$ was effective in:

- $\quad$ Reducing the incidence and severity of PPH.

- Decreased incidence of additional uterotonics agents or other additional surgical interventions.

- Decreased blood transfusion requirement

- Tranexamic acid had no significant adverse effects on neonatal outcome.

\section{Recommendations}

Tranexamic acid should be used before elective cesarean delivery as a prophylactic method for prevention of $\mathrm{PPH}$ even in absence of any risk factors.

Funding: No funding sources Conflict of interest: None declared

Ethical approval: The study was approved by the Institutional Ethics Committee 


\section{REFERENCES}

1. Carroli G, Cuesta C, Abalos E, Gulmezoglu AM. Epidemiology of postpartum haemorrhage: a systematic review. Best Pract Res Clin Obstet Gynecol. 2008;22:999e1012.

2. Say L, Chou D, Gemmill A, Tunçalp Ö, Moller AB, Daniels J, et al. Global causes of maternal death: a WHO systematic analysis. Lancet Global Health. 2014;2(6):e323-33.

3. Menard MK, Main EK, Currigan SM. Executive summary of the revitalize initiative: standardizing obstetric data definitions. Obstet Gynecol 2014;124:150-3.

4. Dahlke JD, Mendez-Figueroa $\mathrm{H}$, Maggio L, Hauspurg AK, Sperling JD, Chauhan SP, et al. Prevention and management of postpartum hemorrhage: a comparison of 4 national guidelines. Am J Obstet Gynecol 2015;213:76.e1-10.

5. Anderson JM, Etches D. Prevention and management of postpartum hemorrhage. Am Fam Physician. 2007; 75:875e82.

6. Sheldon WR, Blum J, Vogel JP, Souza JP, Gülmezoglu AM, Winikoff B. WHO multicounty survey on maternal and newborn health research network. postpartum hemorrhage management, risks, and maternal outcomes: findings from the World Health Organization Multicounty Survey on Maternal and Newborn Health. BJOG. 2014;121:S5e13.

7. Leduc, Leduc D, Senikas V, Lalonde AB, Ballerman $\mathrm{C}$, Biringer A, et al. Active management of the third stage of labor: prevention and treatment of postpartum hemorrhage. J Obstet Gynaecol Canada JOGC. 2009;31(10):980-93.

8. Novikova N, Hofmeyr GJ, Cluver C. Tranexamic acid for preventing postpartum haemorrhage. Cochrane Database Syst Rev. 2015;(6):CD007872.

9. CRASH-2 Trial Collaborators, Shakur H, Roberts I, Bautista R, et al. Effects of tranexamic acid on death, vascular occlusive events, and blood transfusion in trauma patients with significant hemorrhage (CRASH-2): a randomized, placebo-controlled trial. Lancet. 2010;37 (9734):23-32.

10. Roberts I, Kawahara T, $18^{\text {th }}$ Expert Committee on the Selection and Use of Essential Medicines, World Health Organization. Proposal for the inclusion of tranexamic acid (anti-fibrinolytic-lysine analogue) in the WHO model list of essential medicines. Available at: http://www.who.int/selection medicines/committees/expert/18/applications/TRAN EXAMIC_ACID_10_2.pdf?ua=1.

11. Othman ER, Fayez MF, El Aal DE, Mohamed HS, Abbas AM, Ali MK. Sublingual misoprostol versus intravenous oxytocin in reducing bleeding during and after cesarean delivery: A randomized clinical trial. Taiw J Obstet Gynecol. 2016;55(6):791-5.
12. Sentilhes L, Lasocki S, Ducloy-Bouthors AS, Deruelle P, Dreyfus M, Perrotin F, et al. Tranexamic acid for the prevention and treatment of postpartum haemorrhage. Br J Anaesth. 2015;114:576-87.

13. Abbas AM, Amin MT, Ali SS, Salem NZ. Maternal mortality: a tertiary care hospital experience in Upper Egypt. Int $\mathbf{J}$ Reprod Contracept Obstet Gynecol. 2017;5(5):1466-71.

14. WHO and World Bank, Trends in Maternal Mortality: 1990 to 2013. Estimates by WHO, UNICEF, UNFPA, Geneva: WHO, 2014.

15. El-Zanaty F, Way A. Egypt Demographic and Health Survey 2008, Cairo, Egypt: Ministry of Health, ElZanaty, and Associates and Macro International, 2009.

16. Amin TT. Maternal and perinatal mortality: a snapshot on the Egyptian situation. Int Pub Heal Forum. 2014;1(3):1-5.

17. Campbell O, Gipson R, Issa AH, Matta N, El Deeb B, El Mohandes A, et al. National maternal mortality ratio in Egypt halved between 1992-93 and 2000. Bulletin of the World Health Organization. 2005;83:462-71.

18. Gai MY, Wu LF, Su QF, Tatsumoto K. Clinical observation of blood loss reduced by tranexamic acid during and after caesarian section: a multicenter randomized trial. Eur J Obstet Gynecol Reprod Biol. 2004;112:154-7.

19. Sekhavat L, Tabatabaii A, Dalili M, Farajkhoda T, Tafti AD. Efficacy of tranexamic acid in reducing blood loss after caesarean section. J Matern Fetal Neonatal Med. 2009;22:72-5.

20. Simonazzi G, Bisulli M, Saccone G, Moro E, Marshall A, Berghella V. Tranexamic acid for preventing postpartum blood loss after cesarean delivery: a systematic review and meta-analysis of randomized controlled trials. Acta Obstet Gynecol Scand. 2016;95(1):28-37.

21. Novikova N, Hofmeyr GJ, Cluver C. Tranexamic acid for preventing postpartum haemorrhage. Cochrane Database Syst Rev. 2015;6:CD007872.

22. Ahmed MR, Sayed Ahmed WA, Madny EH, Arafa AM, Said MM. Efficacy of tranexamic acid in decreasing blood loss in elective caesarean delivery. J Matern Fetal Neonatal Med. 2015; 28:1014-8.

23. Walzman M, Bonnar J. Effect of tranexamic acid on the coagulation and fibrinolytic systems in pregnancy complicated by placental bleeding. Arch Toxicol Suppl. 1982;5:214-20.

Cite this article as: El-Gaber AEA, Ahmed $\mathrm{HH}$, Khodry MM, Abbas AM. Effect of tranexamic acid in prevention of postpartum hemorrhage in elective caesarean delivery: a randomized controlled study. Int J Reprod Contracept Obstet Gynecol 2019;8:1-5. 